\title{
Clinical Events Pre-specified
}

National Cancer Institute

\section{Source}

National Cancer Institute. Clinical Events Pre-specified. NCI Thesaurus. Code C87852.

An indication or description that a clinical event was previously determined, characterized, or detailed. 